\title{
On recovering Last Interglacial changes in the Antarctic ice sheet
}

\author{
Louise C. Sime', A.E. Carlson² and M. Holloway ${ }^{1,3,4}$
}

The sensitivity of the Antarctic ice sheet to ocean warming is a major source of uncertainty in projecting future sea levels. Antarctic ice from the Last Interglacial sampled in ice cores provides key information to better quantify this

\section{sensitivity.}

Quantifying the sensitivity of the Antarctic ice sheet (AIS) to increasing ocean temperatures is central to improving projections of global sea-level rise. Capron et al. (2014) compiled strong evidence of a Southern Ocean sea-surface temperature anomaly of up to $+3.9 \pm 2.8^{\circ} \mathrm{C} 125,000$ years ago (125 kyr BP) compared to the present, and sea-level indicators for the Last Interglacial (LIG; around 129 to $116 \mathrm{kyr} \mathrm{BP}$ ) suggest that this was the last time that global mean sea level (GMSL) was substantially higher than present (Dutton et al. 2015). This strongly suggests that pinning down the response of the AIS during the LIG should give insight into the last time the AIS was substantially smaller than today.

Ice-sheet modeling, alongside other lines of evidence, suggest the potential for massive loss of West Antarctic ice that is grounded below sea level (e.g. DeConto and Pollard 2016). Isotopic analysis of marine sediments and the NEEM Greenland ice core indicate that Greenland likely provided a relatively small $\sim 2$ m contribution to maximum LIG sea levels (NEEM Project Members 2013; Colville et al. 2011), so the reconstructed LIG GMSL peak of +6 to $9 \mathrm{~m}$ implies that the AIS experienced very significant melt during the LIG (Dutton et al. 2015). However, hunting for more direct evidence of AIS changes during the LIG has thus far proved to be surprisingly difficult, and the ultimate goal of deriving rates of AIS volume change has yet to be achieved.

Terrestrial observations of the extent of the AIS during the LIG are lacking due to subsequent growth of the AIS to its last glacial maximum volume. However, some evidence exists in the marine realm to constrain the LIG AIS. A tephra layer in the ANDRILL sediment core from the Ross Sea shows that at some time in the last $240 \mathrm{kyr}$, the Ross ice shelf was absent, potentially during the LIG (McKay et al. 2012). According to some ice-modeling studies, if the Ross ice shelf was to completely melt, the West Antarctic ice sheet (WAIS) would also deglaciate (e.g. DeConto and Pollard 2016). A recent study from a marine core off East Antarctica used Neodynium isotopes to show that the portion of the AIS overlying the Wilkes subglacial basin significantly retreated to a smaller-than-present extent during the LIG (Wilson et al. 2018). While similar studies near other sectors of the AIS could provide fruitful information on the LIG extent of the AIS, none of these approaches have, on their own, permitted the definitive establishment of AIS changes during the LIG.

\section{The attractions of ice-core data}

Antarctic ice cores are an attractive proposition for reconstructing AIS changes: several ice cores from East Antarctica covering the LIG period have been placed on an improved chronology using new gas and ice stratigraphic links (Bazin et al. 2013). The age uncertainty on this improved chronology is approximately 1500 years during the LIG, which is excellent compared to most other LIG data. Air content measurements from such ice cores have been used to attempt to infer changes in East Antarctic surface elevation over the past $200 \mathrm{kyr}$ (e.g. Martinerie et al. 1994). However, Bradley et al. (2012) demonstrated that existing East Antarctic ice-core sites would experience negligible elevation change in response to a past WAIS collapse, and unknowns in firn modeling make the conversion from air content to atmospheric pressure, needed to infer elevation changes, highly uncertain. However, water isotope $\left(\delta^{18} \mathrm{O}\right)$ data has been measured with a precision generally better than $0.1 \%$ 。 on these same ice cores. These well-dated and precise measurements (Fig. 1) hold the tantalizing prospect of establishing accurate rates of AIS change during the LIG.

Steig et al. (2015) and Holloway et al. (2016) tackled the question of whether changes in the AIS, particularly ice loss from West Antarctica, would exert a significant control over the $\delta^{18} \mathrm{O}$ signal recorded in Antarctic ice cores. Using $\delta^{18} \mathrm{O}$-enabled climate modeling, both demonstrated that significant West Antarctic mass loss or gain would cause major changes that should be observable in ice cores from both West and East Antarctica. Key patterns in ice-core $\delta^{18} \mathrm{O}$ can be generated by melt from the AIS via resulting influences on atmospheric circulation, sea surface temperatures, and sea-ice extent around Antarctica (Holloway et al. 2017).

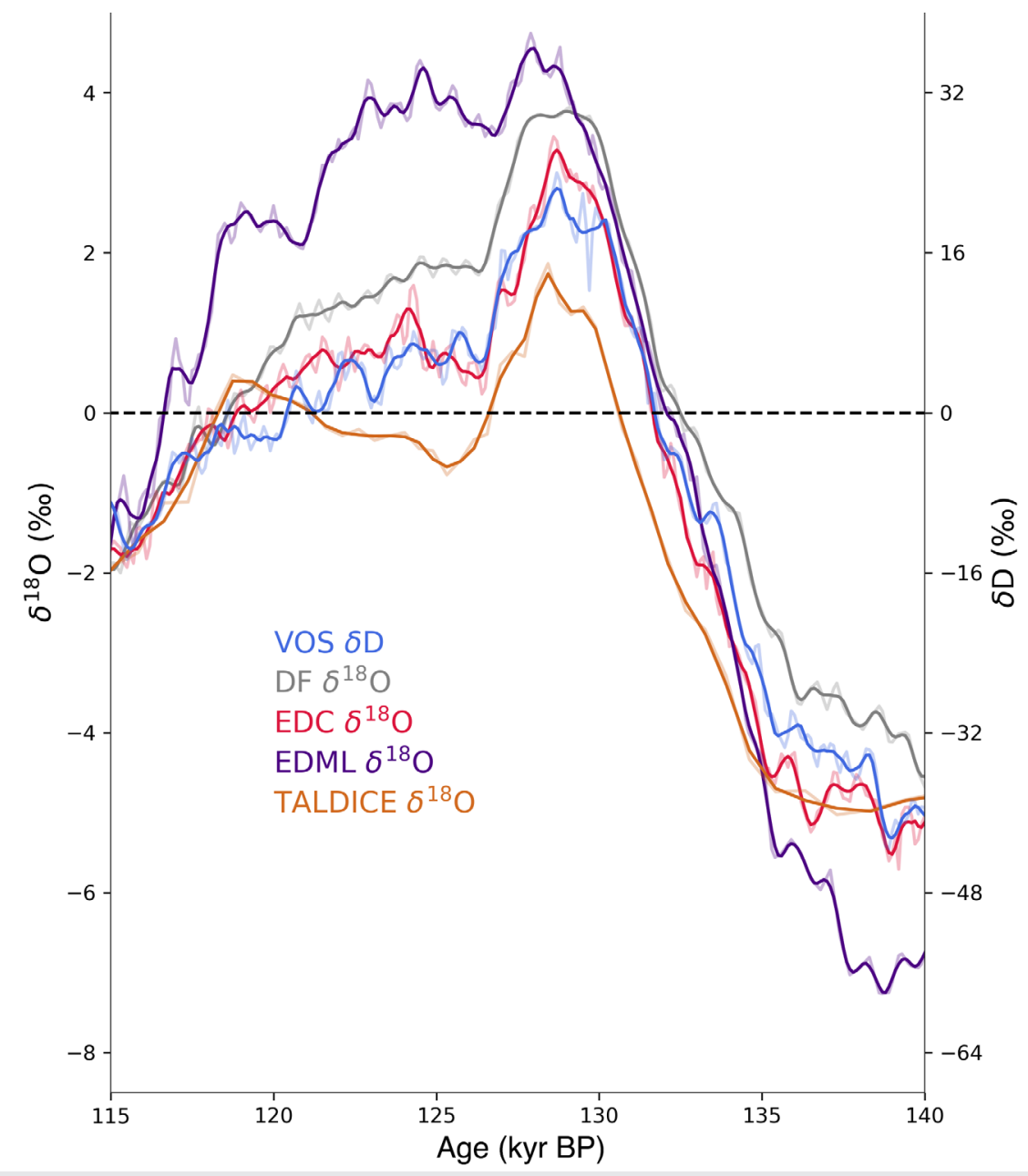

Figure 1: Last interglacial ( 129-116 kyr BP) $\delta D$ and $\delta^{18} \mathrm{O}$ anomalies (relative to the most recent $3 \mathrm{kyr} B P$ ) from the Vostok (VOS), Dome Fuji (DF), EPICA Dome Concordia (EDC), EPICA Dronning Maud Land (EDML), and Talos Dome (TALDICE) ice-core records. Raw ice-core data (light lines) are shown as well as a smoothed record (dark lines). The locations (filled circles) of these ice cores are shown in Figure 2. 

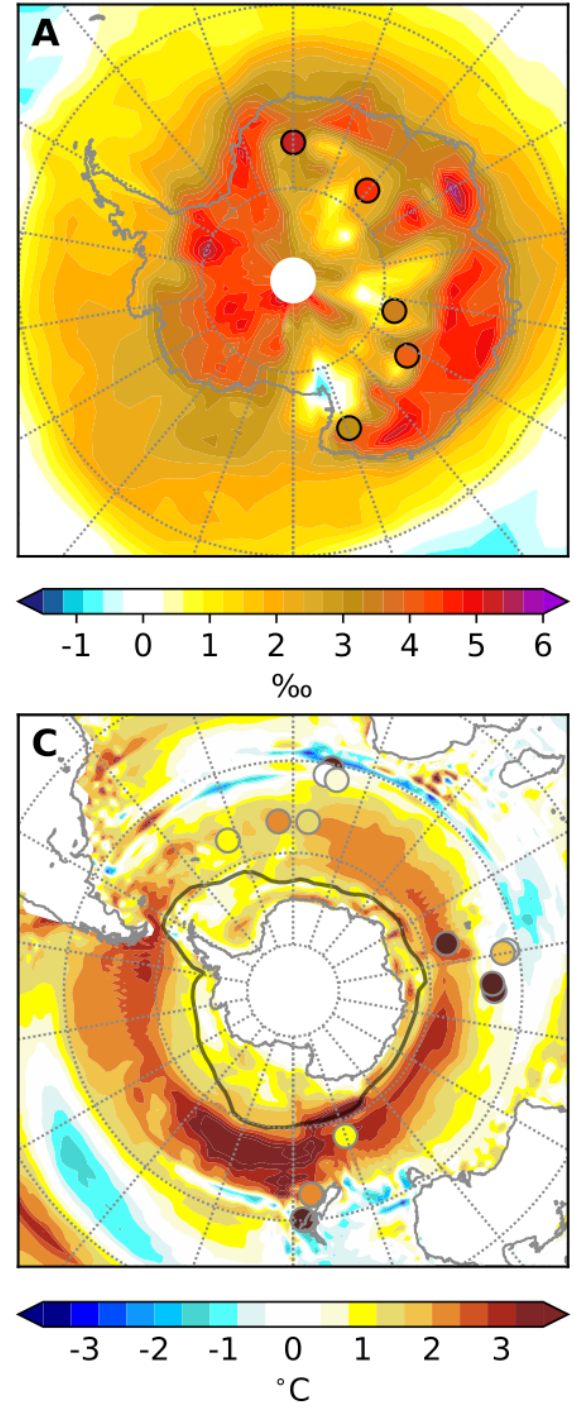

sea-ice retreat in response to relatively high Southern Ocean temperatures, themselves generated by meltwater from the penultimate deglaciation.

- It indicates that the AIS was likely resilient to higher-than-present sea surface temperatures and reduced Antarctic sea ice during the early LIG, since the AIS was largely intact at $128 \mathrm{kyr}$ BP. Parts of the AIS could, however, have melted shortly after $128 \mathrm{kyr} \mathrm{BP}$ (e.g. Fig. 2b) in direct response to the warming, but this has yet to be established.

\section{Next steps}

Focused study on the period following the ice-core $\delta^{18} \mathrm{O}$ peak ( 125 kyr BP; Fig. 1) may provide important information on the magnitude and timescales of AIS change in response to a period of reduced sea ice and Southern Ocean warming. An example is illustrated in Figure $2 \mathrm{~b}$; ice-core $\delta^{18} \mathrm{O}$ data at 125 kyr BP may be better explained using a reduced AIS configuration relative to present day, suggesting substantial continental ice loss in the 3 kyr period following the reconstructed LIG Antarctic sea-ice minimum.

Based on these recent advances, we suggest that the next steps should include: (i) checking, using $\delta^{18} \mathrm{O}$-enabled models, how ice cores may respond to other types and magnitudes of AIS changes (e.g. Fig. 2b), (ii) assessing whether our current ice-core data are sufficient to establish AIS changes; and (iii) obtaining new LIG ice-core data as necessary to constrain the models. Once these steps have been taken, we may find ourselves in a position to be able to pin down the most likely timing and contribution of the AIS to GMSL during this past warm interval.

\section{AFFILIATIONS}

'Ice Dynamics and Paleoclimate, British Antarctic Survey, Cambridge, UK

${ }^{2}$ College of Earth, Ocean, and Atmospheric Sciences, Oregon State University, Corvallis, USA

${ }^{3}$ Data Science Division, National Physical Laboratory, Teddington, UK

${ }^{4}$ School of Geographical Sciences, University of Bristol, UK

\section{CONTACT}

Louise C. Sime: Isim@bas.ac.uk

\section{REFERENCES}

Bazin L et al. (2013) Clim Past 9: 1715-1731

Bradley S et al. (2012) Glob Planet Change 88-89: 64-75 Capron E et al. (2014) Quat Sci Rev 103: 116-133 Colville EJ et al. (2011) Science 333: 620-623 DeConto RM, Pollard D (2016) Nature 531: 591-597

Dutton A et al. (2015) Science 349: aaa4019 Holloway MD et al. (2016) Nature Commun 7: 12293 Holloway MD et al. (2017) Geophys Res Lett 44: $11,129-11,139$

Holloway MD et al. (2018) Geophys Res Lett 45: $11,921-11,929$

Martinerie P et al. (1994) J Geophys Res 99: 10565-10576 McKay R et al. (2012) Quat Sci Rev 34: 93-112 NEEM Project Members (2013) Nature 493: 489-494 Steig EJ et al. (2015) Geophys Res Lett 42: $4862-4868$ Wilson DJ et al. (2018) Nature 561: 383-386 (i) Meltwater from Northern Hemisphere ice sheets caused warming of the Southern Ocean; (ii) This in turn melted Antarctic
Of course, the work described above does cover AIS change throughout the entire LIG. In particular, determining how the AIS may have responded after the $128 \mathrm{kyr}$ BP ice-core structed (itself a response to the reconice retreat; e.g. Fig 2c) is yet to be a focus of ice-core modeling research (e.g. Holloway et al. 2016). The research performed to date does, however, provide key results to build upon:

- It establishes confidence in both climate models and in our understanding of LIG atmosphere and ocean dynamics. It also means that we now know with some confidence that the LIG $\delta^{18} \mathrm{O}$ peak (shown in Fig. 1) was caused primarily by Antarctic 